\title{
MicroRNA-21 regulates T-cell apoptosis by directly targeting the tumor suppressor gene Tipe2
}

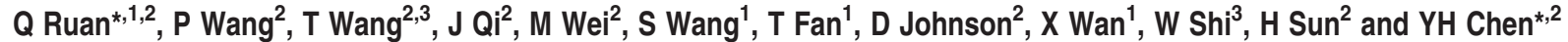

MicroRNAs (MiRs) are short noncoding RNAs that can regulate gene expression. It has been reported that miR-21 suppresses apoptosis in activated T cells, but the molecular mechanism remains undefined. Tumor suppressor Tipe2 (or tumor necrosis factor- $\alpha$-induced protein 8 (TNFAIP8)-like 2 (TNFAIP8L2)) is a newly identified anti-inflammatory protein of the TNFAIP8 family that is essential for maintaining immune homeostasis. We report here that miR-21 is a direct target of nuclear factor- $\kappa B$ and could regulate Tipe2 expression in a Tipe2 coding region-dependent manner. In activated T cells and macrophages, Tipe2 expression was markedly downregulated, whereas miR-21 expression was upregulated. Importantly, Tipe2-deficient $\mathrm{T}$ cells were significantly less sensitive to apoptosis. Conversely, overexpression of Tipe2 in EL-4 T cells increased their susceptibility to activation-induced apoptosis. Therefore, Tipe2 provides a molecular bridge between miR-21 and cell apoptosis; miR-21 suppresses apoptosis in activated T cells at least in part through directly targeting tumor suppressor gene Tipe2.

Cell Death and Disease (2014) 5, e1095; doi:10.1038/cddis.2014.47; published online 27 February 2014

Subject Category: Immunity

Over the past decade, the importance of microRNAs (miRNAs) in the regulation of cell functions has become more and more apparent. These small but potent regulators have important roles in a range of processes, including hematopoietic cell development, immunity, and carcinogenesis. ${ }^{1-7}$ MiRNAs are small ( 22 nucleotide), noncoding RNAs that can pair with complementary sequences within mRNA molecules. Its binding can trigger mRNA destabilization and/or translational repression, leading to a decrease in the protein encoded by their cognate mRNAs. ${ }^{8,9}$ One of the miRNAs, namely miR-21, was identified as being significantly overexpressed in a wide range of solid tumors such as breast, lung, colon, gastric, and pancreatic cancers. ${ }^{10-20}$ In addition, miR-21 upregulation is associated with the development of a variety of inflammatory diseases including colitis and psoriasis. ${ }^{21,22}$ MiR-21 acts as an antiapoptotic agent in a variety of cell types. ${ }^{23,24}$ Recently, it was reported that miR-21 suppresses apoptosis of murine and human primary $\mathrm{T}$ cells and modulates cytokine production. ${ }^{25-28}$

Proliferative expansion of lymphoid cells is required for effective immune responses against invading microorganisms, but the expanded effector cells must be eliminated to prevent overaccumulation of cells after the infection is controlled. ${ }^{29}$ The cell number, repertoire diversity, and self-tolerance of mature $\mathrm{T}$ lymphocytes are tightly controlled by a process called programmed cell death or apoptosis. Apoptosis of mature T lymphocytes is regulated by extensive networks of signal-transduction pathways. This ensures controlled activation and expansion of cells during immune responses and apoptotic deletion of lymphoid cells that are no longer needed at the end of immune responses. ${ }^{30} \mathrm{~T}$-cell apoptosis occurs in at least two major forms: antigen-driven and lymphokine withdrawal-induced. Active antigen-driven death is mediated by the expression of death molecules such as Fas ligand. The transcription factor nuclear factor- $\mathrm{KB}$ (NF-KB) is activated by survival factors and cytokines such as tumor necrosis factor- $\alpha$ (TNF- $\alpha$ ) ${ }^{31}$ In most cell types, NF- $\kappa$ B strongly inhibits apoptosis. ${ }^{32}$ Genetic deficiencies of the $\mathrm{NF}-\mathrm{\kappa B}$ transcription factor increase spontaneous and TNF- $\alpha$-induced lymphocyte apoptosis. ${ }^{33}$ How this transcription factor promotes cell survival is not fully understood, but it presumably relates to the induction of survival genes or the inhibition of death genes.

Tipe2, or TNF- $\alpha$-induced protein 8 (TNFAIP8)-like 2 (TNFAIP8L2), is a member of the TNFAIP8 family, which is preferentially expressed in hematopoietic cells. ${ }^{34,35}$ It is significantly downregulated in patients with infectious or autoimmune disorders and its expression inversely correlates with disease progression. ${ }^{36}$ Germline deletion of Tipe2 results in fetal inflammation and hypersensitivity to Toll-like receptor

\footnotetext{
${ }^{1}$ Institute of Biomedicine and Biotechnology, Shenzhen Institutes of Advanced Technology, Chinese Academy of Sciences, Shenzhen 518055, People's Republic of China; ${ }^{2} 713$ Stellar-Chance Laboratories, Department of Pathology and Laboratory of Medicine, University of Pennsylvania Perelman School of Medicine, Philadelphia, PA 19104, USA and ${ }^{3}$ Shandong Eye Institute, Qingdao 266071, People's Republic of China

${ }^{*}$ Corresponding author: Q Ruan, Shenzhen Institutes of Advanced Technology, Chinese Academy of Sciences, Xili Nanshan, 1068 Xueyuan Boulevard, Shenzhen 518055, People's Republic of China. Tel: +86 755 86585201; Fax: +86 755 86585222; E-mail: qg.ruan@ siat.ac.cn

or YH Chen, 713 Stellar-Chance Laboratories, Department of Pathology and Laboratory Medicine, University of Pennsylvania Perelman School of Medicine, 422 Curie Boulevard, Philadelphia, PA 19104, USA. Tel: +1 215898 4671; Fax: +1 215573 3434; E-mail: youhaic@ gmail.com

Keywords: MiR-21; TNFAIP8; Tipe2; apoptosis; NF- $\kappa$ B

Abbreviations: MiR-21, microRNA 21; Tipe2, tumor necrosis factor- $\alpha$-induced protein 8-like 2; NF- $\kappa$ B, nuclear factor- $\kappa$ B; qRT-PCR, quantitative reverse-transcription PCR; ChIP, chromatin immunoprecipitation; Pdcd4, programmed cell death protein 4; AP-1, activator protein-1; PTEN, phosphatase and tensin homolog; TGFBI, transforming growth factor- $\beta$-induced; Btg2, BTG family member 2 ; $3^{\prime}$-UTR, $3^{\prime}$-untranslated region; 7AAD, 7 -aminoactinomycin D

Received 08.10.13; revised 30.12.13; accepted 17.1.14; Edited by M Agostini
} 
and T-cell receptor stimulation. ${ }^{37}$ Tipe2 overexpression induced cell death and significantly inhibited Ras-induced tumorigenesis in mice. ${ }^{38}$

We report here that the three aforementioned factors, $\mathrm{NF}-\kappa \mathrm{B}, \mathrm{miR}-21$, and Tipe2, form a unique regulatory axis that controls T-lymphocyte apoptosis. This axis is involved in $\mathrm{NF}-\kappa \mathrm{B}-$ mediated inhibition of T-cell death and may serve as a unique target for the regulation of immune responses.

\section{Results}

Tipe2 expression is downregulated in $\mathbf{T}$ cells and macrophages after activation. Tipe 2 is expressed preferentially by immune cells. To test the expression of Tipe 2 in T cells, quantitative reverse-transcription PCR (qRT-PCR) analysis of Tipe2 mRNA level was performed for CD4 + T cells either untreated or treated with anti-CD3 plus anti-CD28 for various times (Figure 1a). We found that Tipe2 mRNA level in $T$ cells was decreased by threefold as early as $4 \mathrm{~h}$ after activation. To test the expression of Tipe2 protein in $\mathrm{T}$ cells, western blot analysis were performed for naive CD4 + T cells either untreated or treated with anti-CD3 plus anti-CD28 for $5 \mathrm{~h}$. Tipe2 protein level was markedly decreased in $\mathrm{T}$ cells after treatment (Figure $1 \mathrm{~b}$ ). In addition, blocking NF- $\kappa \mathrm{B}$ activation with Bay 11-7082 in $\mathrm{T}$ cells treated with anti-CD3 plus anti-CD28 completely rescued the defect in Tipe2 expression (Figure 1c), indicating that TCR stimulation downregulates Tipe2 by NF- $\kappa$ B activation.

NF- $\kappa$ B regulates miR-21 expression. Consistent with published data that $\mathrm{miR}-21$ is a potential target of $\mathrm{NF}-\kappa \mathrm{B},{ }^{39-41}$ we found that miR-21 expression was induced by anti-CD3 plus anti-CD28 treatment in CD4 $+\mathrm{T}$ cells
(Figure 2a) and LPS treatment in macrophages (Figure 2b), but was partially blocked by the NF-кB inhibitor Bay 11-7082 (Figures $2 \mathrm{a}$ and $\mathrm{b}$ ). A close examination of miR-21 promoter region using the Transcription Element Search System (TESS, University of Pennsylvania, Philadelphia, PA, USA) software revealed two putative NF- $\kappa$ B binding sites (NF- $\kappa$ B no. $1,-20$ to -12 , and $N F-\kappa B$ no. $2,-205$ to -196$)$. Because data from several groups including ours showed that LPS resulted in the induction of miR-21 via NF- $\kappa \mathrm{B}$, macrophages were used to determine the roles of $\mathrm{NF}-\kappa \mathrm{B}$ during the induction of miR-21. Luciferase reporter assay was used to determine whether the two NF- $\kappa \mathrm{B}$ sites were required for $\mathrm{NF}-\kappa \mathrm{B}$ action. Our data showed that while LPS induced miR-21 promoter activity, mutation of either $\mathrm{NF}-\kappa \mathrm{B}$ binding site almost completely diminished it (Figure 2c). These data indicate that both NF- $\kappa \mathrm{B}$ no. 1 and $\mathrm{NF}-\kappa \mathrm{B}$ no. 2 sites were required for the NF- $\kappa \mathrm{B}$ response.

To directly test NF- $\kappa \mathrm{B}$ binding to the identified sequences of the miR-21 promoter, we performed nucleotide pull-down analyses using both wild-type (WT) and mutant nucleotides. We found that $\mathrm{p} 65$, one of the NF- $\mathrm{NB}$ family members, readily bound to the nucleotides of both NF- $\kappa$ B sites, but not their mutants (Figure $2 d$ ). To establish whether NF- $\kappa$ B binds to the miR-21 promoter in live cells, we performed chromatin immunoprecipitation (ChIP) analysis. The miR-21 DNAprotein complexes were precipitated using specific antibodies to p65 and RNA polymerase II in bone marrow-derived macrophages either untreated or treated for $2 \mathrm{~h}$ with LPS. The nature of the precipitated DNA was then defined by PCR using primers specific for NF- $\kappa$ B no. 1 site. We found that in untreated macrophages, the miR-21 promoter exhibited weak p65 or RNA polymerase II binding. At $2 \mathrm{~h}$ after LPS treatment, p65 and RNA polymerase II binding to the miR-21 promoter
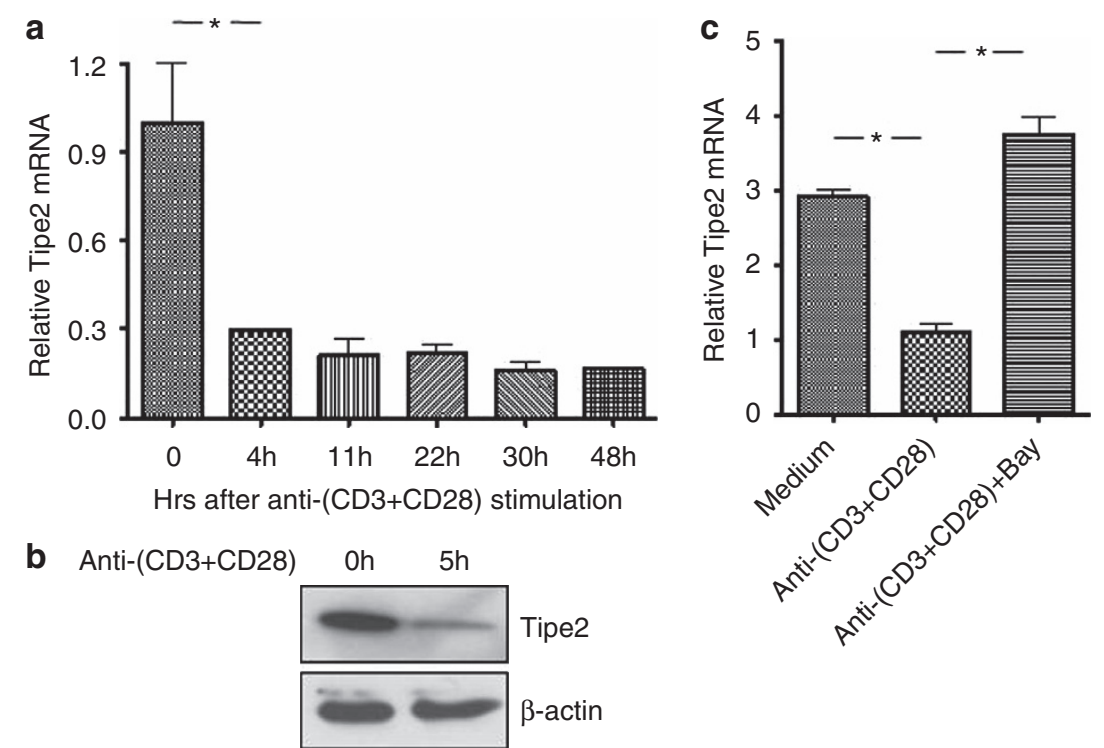

Figure $1 \mathrm{NF}-\kappa \mathrm{B}$-dependent downregulation of Tipe2 in T cells and myeloid cells. (a) Murine naive CD4 $+\mathrm{T}$ cells were either untreated or treated with plate-bound antiCD3 $(1 \mu \mathrm{g} / \mathrm{ml})$ and soluble anti-CD28 $(1 \mu \mathrm{g} / \mathrm{ml})$ for the indicated times, and Tipe2 mRNA levels were determined by quantitative PCR. (b) Murine naive CD4 + T cells were either untreated or treated with plate-bound anti-CD3 $(1 \mu \mathrm{g} / \mathrm{ml})$ and soluble anti-CD28 $(1 \mu \mathrm{g} / \mathrm{ml})$ for $5 \mathrm{~h}$, Tipe2 protein levels were determined by western blot analysis. (c) Murine naive CD4 $+\mathrm{T}$ cells were treated as in (a) for $4 \mathrm{~h}$ in the absence or presence of NF- $\kappa$ B inhibitor Bay 11-7082. Tipe2 mRNA levels were determined by quantitative PCR. ${ }^{*} P<0.02$. The results are representative of three independent experiments 
was noticeably increased (Figure $2 \mathrm{e}$ ). These results are consistent with published data that miR-21 is transcribed by RNA polymerase II and indicate that miR-21 is a direct target of NF- $\kappa \mathrm{B}$.

Tipe2 is a direct target of miR-21. Our data presented above showed an inverse correlation between miR-21 and tumor suppressor Tipe2 expression in activated immune cells, which appears to be NF- $\kappa \mathrm{B}$ dependent. This prompted us to speculate that Tipe2 could be a target of miR-21. A sequential three-step approach was used to test this possibility. First, putative miR-21 binding sites were identified by bioinformatic analysis; second, functional implications of miR-21 binding to Tipe2 mRNA was validated by luciferase reporter assay; and finally, the relationship between miR-21 and Tipe2 mRNA expression was examined in overexpression systems.

The potential miR-21 binding sites were predicted using MiRecords. However, we did not detect any putative miR-21 binding site within the $3^{\prime}$-untranslated region $\left(3^{\prime}\right.$-UTR) of TIPE2 mRNA. Instead, putative miR-21 binding site $(+396$ to +417$)$, as well as miR-155 $(+499$ to +511$)$ and a

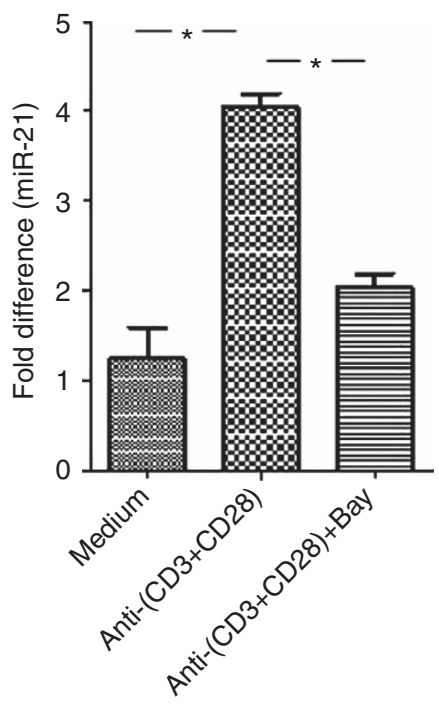

b

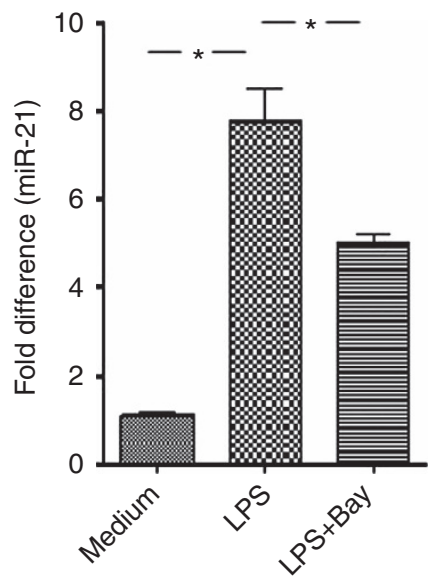

c

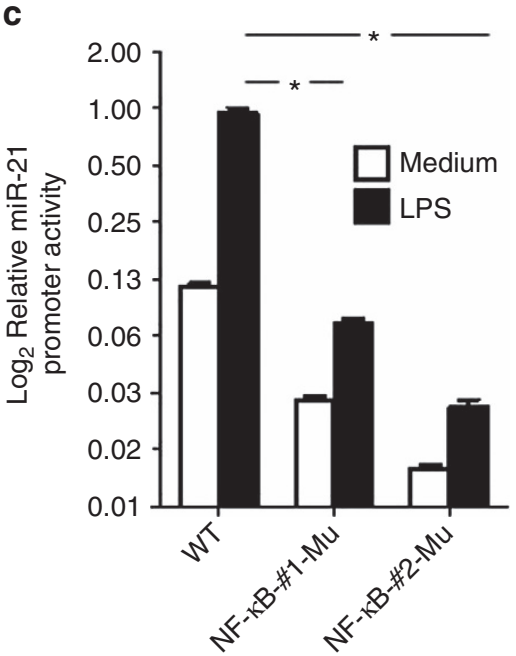

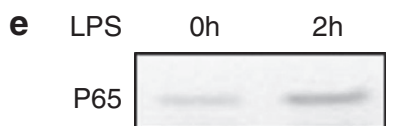
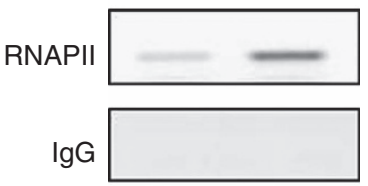

Input

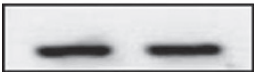

Figure 2 NF- $\kappa$ B binds to and activates the miR-21 promoter. (a) Murine naive CD4 + T cells were either untreated or treated with plate-bound anti-CD3 $(1 \mu \mathrm{g} / \mathrm{ml})$ and soluble anti-CD28 $(1 \mu \mathrm{g} / \mathrm{ml})$ for $6 \mathrm{~h}$ in the absence or presence of NF- $\kappa$ B inhibitor Bay 117-82, and miR-21 levels were determined by quantitative PCR. ${ }^{*} P<0.01$. (b) Murine bone marrow-derived macrophages were either untreated or treated with LPS (100 ng/ml) for $4 \mathrm{~h}$ in the absence or presence of NF- $\kappa$ B inhibitor Bay 117-82. MiR-21 levels were determined by quantitative PCR. ${ }^{*} P<0.02$. (c) RAW264.7 cells were transiently transfected with WT or NF- $k B$ site-mutated murine miR-21 promoter luciferase construct. After $24 \mathrm{~h}$, cells were either untreated or treated with LPS $(100 \mathrm{ng} / \mathrm{ml})$ for $6 \mathrm{~h}$, and the luciferase activities measured. The promoter activity is presented as fold increase over untreated cells transfected with NF- $\kappa$ B site no. 2 mutated construct. To normalize the transfection efficiency across samples, the Renilla luciferase expression vector $\mathrm{pRL}-\mathrm{TK}$ was included as an internal control. ${ }^{*} P<0.01$. (d) Nuclear extracts were prepared from mouse bone marrow-derived macrophages after stimulation for $2 \mathrm{~h}$ with LPS. Biotinylated miR-21 oligonucleotides containing NF- $\kappa$ B binding site nos. 1 or 2 or their mutants were absorbed by streptavidin-agarose beads, and then added to the nuclear extracts. The amount of 65 proteins in the precipitates were assessed by immunoblotting with anti-p65. (e) Mouse bone marrow-derived macrophages were treated with LPS (100 ng/ml). After $2 \mathrm{~h}$, cells were fixed, and ChIP was performed using anti-p65, anti-RNA polymerase II (Polll), or control IgG. Immunoprecipitated DNA was analyzed by PCR using primers for NF- $\kappa$ B site on miR-21 promoter. Data are representative of two independent experiments 
miR-23b $(+592$ to +612$)$ binding sites, was identified in the coding region of Tipe2. Like miR-21, miR-155 and miR-23b are also NF- $\mathrm{KB}$ target genes.

We next examined whether the coding region of Tipe2 $(+307$ to +644$)$ could downregulate protein expression using Dual Luciferase Reporter Assay System (Promega, Madison, WI, USA). The luciferase reporter vectors contained either the $3^{\prime}$-UTR or Tipe2 coding region $(+307$ to +644$)$ downstream of the firefly luciferase gene. Consistent with the bioinformatic result, Tipe2 coding region $(+307$ to +644$)$, but not $3^{\prime}$-UTR, resulted in a significant downregulation of luciferase activity (Figure 3a). Co-transfection of p65 overexpression construct resulted in further downregulation of luciferase activity (Figure $3 b$ ). These data indicate that a regulatory element present in the Tipe 2 coding region $(+307$ to +644 ) could downregulate Tipe2 gene expression. To narrow down the responsive region, we performed deletional analysis. We found that nucleotides +389 to +432 were required for the downregulation of luciferase activity, which contains the predicted miR-21 binding site (Figure 4a).

To validate the miRNA-target interactions, WT and miR-21 binding site-mutated Tipe2 (Figure 4b) were cloned into luciferase reporter plasmid downstream of the firefly luciferase gene. As shown in Figure 4c, miR-21 binding site-mutated Tipe2 coding region $(+307$ to +644$)$ was unable to downregulate luciferase activity. These data further confirm that miR-21 targets Tipe2 in a coding region-dependent manner.

mRNA degradation is regarded as a major mechanism for miRNA regulation of target gene expression. To determine

a

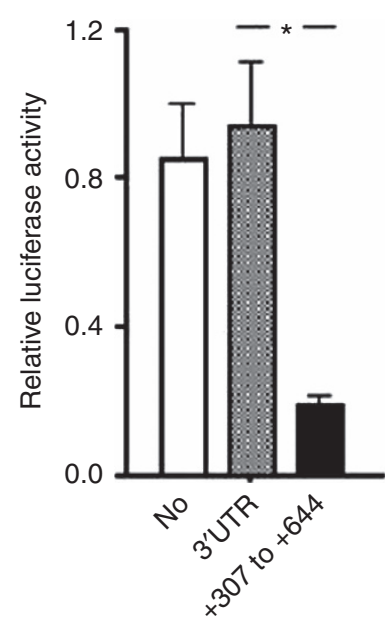

b

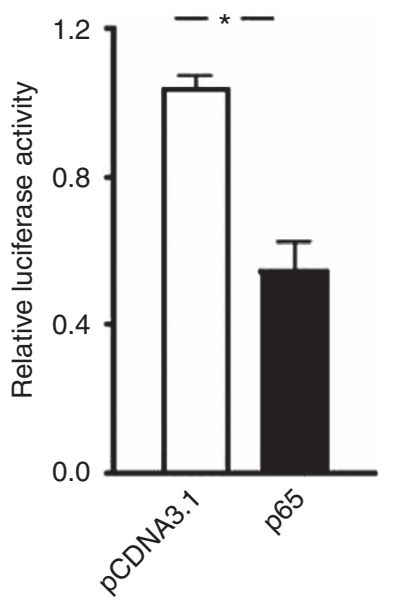

Figure 3 Tipe2 coding region, but not $3^{\prime}-U T R$, is responsible for the downregulation of Tipe2. EL4 cells were transiently transfected with murine Tipe2 promoter luciferase construct with Tipe2 $3^{\prime}$-UTR $(\mathbf{A})$ or coding region $(+307$ to +644 ) (a and $\mathbf{b}$ ) inserted downstream of the luciferase gene but upstream of polyA signal sequence. For (b), expression vector for full-length p65, or the empty vector as indicated, was co-transfected. At $24 \mathrm{~h}$ after transfection, cells were treated with phorbol myristyl acetate (PMA) $(50 \mathrm{ng} / \mathrm{ml})$ and ionomycin $(1 \mu \mathrm{M})$ for $5 \mathrm{~h}$, and the luciferase activities measured. The promoter activity is presented as fold increase over cells transfected with murine miR-21 promoter only luciferase construct (a) or empty vector (b). To normalize the transfection efficiency across samples, the Renilla luciferase expression vector pRLTK was included as an internal control. ${ }^{\star} P<0.01$. Data are representative of three independent experiments whether miR-21 suppresses endogenous Tipe2 expression through mRNA degradation, EL4 (Figure 5a) and RAW264.7 (Figure 5b) cells were transfected with miR-21 mimic, and the expression of Tipe2 and programmed cell death protein 4 (Pdcd4) mRNA was examined by qRT-PCR. We found that overexpression of miR-21 could significantly reduce the expression of both Tipe 2 and Pdcd 4 mRNA. These data suggest that miR-21 negatively regulates endogenous Tipe2 mRNA expression through mRNA degradation.

MiR-21 regulates T-cell apoptosis through Tipe2. Homeostatic balance within the immune system is maintained by a myriad of mechanisms, which include the regulation of immune cell activation and programmed cell death. Tipe2 is a new death-inducing protein that governs both apoptosis and immune cell function. Tipe2 binds to caspase- 8 and inhibits activator protein-1 (AP-1) and $\mathrm{NF}-\kappa \mathrm{B}$ activation while promoting Fas-induced apoptosis. ${ }^{37}$ We found that Tipe2-deficient CD4 + T cells were resistant to apoptosis induced by TCR activation (Figure 6a).

To explore the relevance of Tipe2 to miR-21-related functions, we performed a functional rescue experiment by overexpressing Tipe2 in cells ectopically expressing miR-21. As shown in Figure 5b, overexpression of Tipe2 reduced, but not fully eliminated, the antiapoptotic role of miR-21 (Figure 6b). These data indicate that although other possible mediators exist, one possible downstream target of miR-21 that has a role in activation-induced T-cell apoptosis is Tipe2.

\section{Discussion}

Tipe2 is expressed preferentially in lymphoid tissues and a small number of non-lymphoid tissues. Within the lymphoid compartment, T cells appear to express high level of Tipe2 protein. High levels of Tipe2 were also detected in monocyte/ macrophage-derived cell lines. ${ }^{34,35}$ Our data showed that Tipe2 expression is downregulated in T cells and macrophages after activation. This is consistent with reports that Tipe2 is downregulated in patients with chronic inflammatory diseases such as systemic lupus erythematosus and hepatitis, and its expression inversely correlates with disease progression.

Annotation of miRNA genes has revealed that the majority of the miRNAs are intergenic. Pri-miR-21 is one of the first human miRNA genes whose regulation was extensively studied. Pri-miR-21 has its own promoter region and miR-21 was one of the first miRNAs to be identified as transcribed by RNA polymerase II. Potential promoter regions of pri-miR-21 have been thoroughly studied. The actual size of pri-miR-21, the transcriptional start site and minimal promoter region of pri-miR-21 are still subjects of debate. It has been shown that multiple transcription factors such as STAT3, NF- $\kappa \mathrm{B}$, and AP-1 can regulate miR-21 expression. ${ }^{39-45}$ Our data indicate that $\mathrm{NF}-\kappa \mathrm{B}$ regulates miR-21 expression by directly binding to its promoter.

MiRNAs are small ( $\sim 22 \mathrm{nt})$ non-coding RNAs that regulate protein-coding genes through post-transcriptional gene silencing. A protein complex known as the RNA-induced silencing complex is guided to mRNAs with partial complementarity to the miRNA, leading to a reduced translation rate and/or 

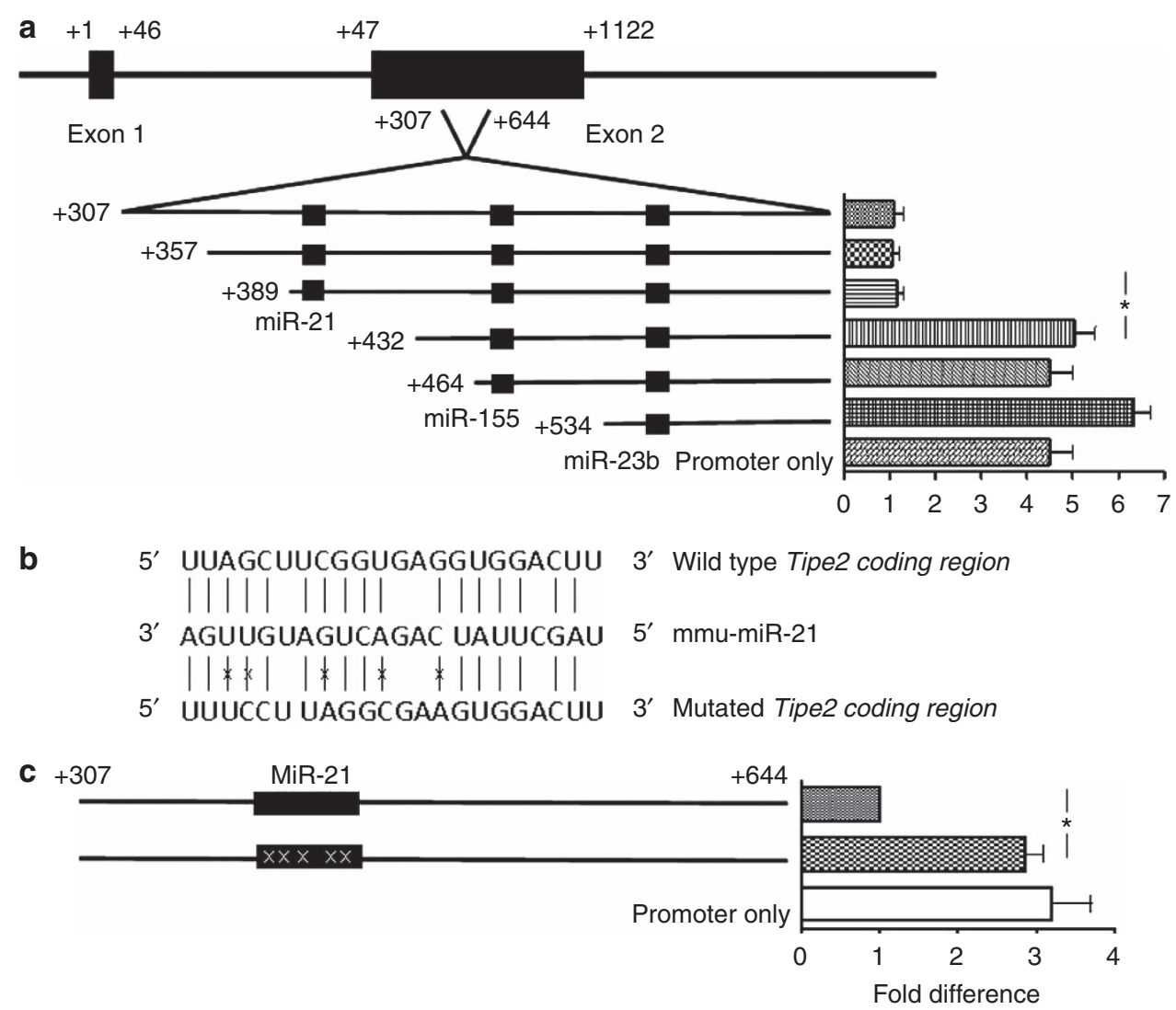

Figure 4 MiR-21 targets Tipe2 in a coding region-dependent manner. (a) Deletion mutants of Tipe2 coding region $(+307$ to +644$)$ were analyzed in the luciferase reporter assay. Putative binding site for miR-21, miR-155 and miR-23b are indicated. (b) The predicted miR-21 binding site on murine Tipe2 coding region and the mutation strategy is shown. The ' $X$ ' indicates the mutated sites. (c) WT and miR-21 binding site-mutated Tipe2 coding region constructs were analyzed in the luciferase reporter assay. The ' $X$ ' indicates the mutated sites. ${ }^{*} P<0.02$. Data are representative of three independent experiments

increased mRNA degradation. To date, a large body of literature has provided evidence that the expression of miRNAs is dysregulated in cancer. MiR-21 is referred to as an 'oncomiR' because it downregulates tumor suppressor genes, such as Pdcd4, phosphatase and tensin homolog deleted on chromosome 10 (PTEN), transforming growth factor- $\beta$-induced (also known as Big-h3), BTG family member 2 (Btg2) and reversion-inducing-cysteine-rich protein with kazal motifs (Reck). ${ }^{46-55}$ Our data showed that Tipe2 is a new direct target of miR-21. The identification of miR-21 binding site within Tipe2 coding region instead of $3^{\prime}$-UTR is not surprising because it has been reported that some miRNA species regulate gene expression by targeting coding regions. $^{56,57}$

MiR-21 acts as an antiapoptotic agent in a variety of cell types. Recently, it has been reported that miR-21 suppresses apoptosis of murine and human primary $T$ cells and modulates cytokine production. Specific inhibition of miR-21 increased the apoptosis rate of activated T cells. ${ }^{26,28,58,59}$ However, the molecular pathway by which miR-21 regulates $\mathrm{T}$-cell apoptosis is still elusive. It has been shown that PTEN, a validated miR21 target in various malignancies, was not involved in this process. ${ }^{28} \mathrm{~T}$-cell apoptosis has an important role after antigen activation in governing immune homeostasis and tolerance. Identification of novel miR-21-regulated targets is a necessary step to understand miR-21 functions in activation-induced
T-cell apoptosis. Our data indicate that miR-21 suppresses apoptosis in activated $T$ cells at least in part through directly targeting tumor suppressor gene Tipe2, although it is possible that they could still act independent of each other.

In summary, we have shown that miR-21 could directly target tumor suppressor gene Tipe2, and NF- $\kappa \mathrm{B}$ inhibits activation-induced T-cell apoptosis through the miR-21-Tipe2 axis (Figure 7). A large number of diseases such as diabetes, rheumatoid arthritis, and multiple sclerosis appear to have a T-cell component. Better understanding the molecular mechanism of activation-induced T-cell apoptosis may aid in the development of antigen-induced apoptosis therapies that reduce or eliminate pathogenic $T$ cells.

\section{Materials and Methods}

Mice. C57BL/6J (B6) mice that carry a Tipe2 gene null mutation were generated by backcrossing Tipe2 $2^{-/-} 129$ mice to B6 mice for 12 generations. WT C57BL/6J mice and mir21 $1^{-1-}$ mice were purchased from the Jackson Laboratory (Bar Harbor, ME, USA). Mice were housed in the University of Pennsylvania Animal Care Facilities under pathogen-free conditions. All animal procedures used were preapproved by the Institutional Animal Care and Use Committee of the University of Pennsylvania.

RNA isolation and real-time PCR. Total RNA was extracted using TRIzol (Life Technologies, Grand Island, NY, USA) according to the manufacturer's instructions. Reverse transcription was performed using oligo dT primers or specific primers for miR-21 and control U6 (Life Technologies). Quantitative 
real-time PCR was carried out in the Applied Biosystems 7500 system using Power SYBR Green PCR Master Mix (Life Technologies). Relative level of gene expression was determined using GAPDH (for Tipe2 and Pdcd4) or U6 (for
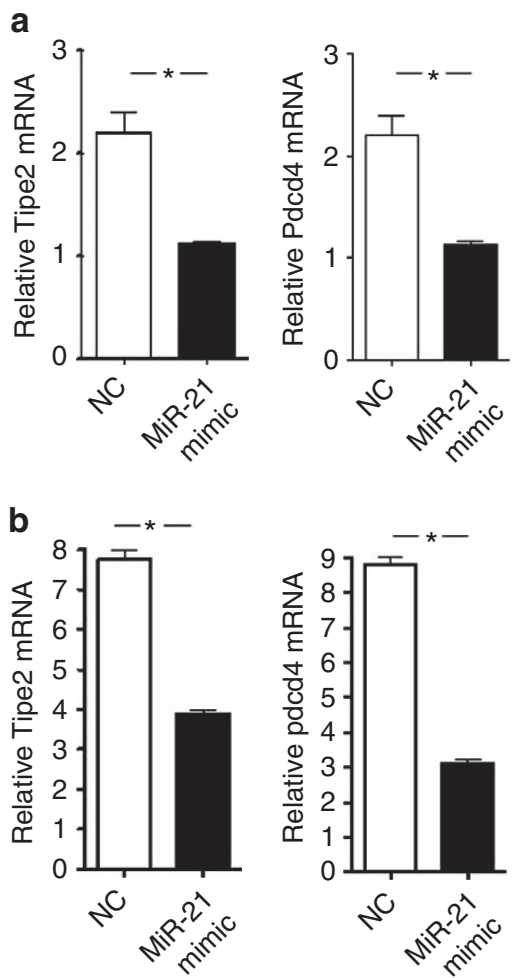

Figure 5 MiR-21 regulates endogenous Tipe2 expression. RAW264.7 (a) and EL4 (b) cells were transfected with miR-21 mimic or negative control as indicated. At $24 \mathrm{~h}$ after transfection, miR-21, Tipe2 and Pdcd4 mRNA levels were determined by real-time RT-PCR. ${ }^{*} P<0.02$. Data are representative of three independent experiments
miR-21) as the control. The primers used to amplify miR-21 and U6 were purchased from Life Technologies. Other primers used in this study are: Tipe2-F, 5'-AACATCCAAGGCCAGACTGG-3'; Tipe2-R, 5'-GAGATGCGCCACGGACCG A-3'. Pdcd4-F, 5'-ATGGATATAGAAAATGAGCAGAC-3'; Pdcd4-R, 5'-AAGAGTC TGGACCGCCTATC-3'. Gapdh-F, 5'-AGTATGACTCCACTCACGGCAA-3'; Gapdh-R, 5'-TCTCGCTCCTGGAAGATGGT-3'.

Flow cytometry and antibodies. Flow cytometric analyses were used to determine the rate of apoptosis of T cells. After treatment, cells were stained with annexin $\mathrm{V}$ and 7-aminoactinomycin $\mathrm{D}$ as per the manufacturer's instruction (BD Biosciences, San Jose, CA, USA). Stained cells were analyzed on a FACSCalibur flow cytometer (BD Biosciences). Data were analyzed with FlowJo software (TreeStar Inc, Ashland, OR, USA).

Transient transfection. MiR-21 (miR-21 mimic; Life Technologies) and Tipe2 plasmid transfection of EL4 cell line was carried out using Amaxa electroporation apparatus (Amaxa Biosystems, Gaithersburg, MD, USA), as per the manufacturer's protocols, for the cell line (Amaxa Cell Line Nucleofector Kit L, Amaxa Biosystems). Cells were collected $24 \mathrm{~h}$ later and subjected to further treatments.

Cell culture. Naive CD4 $+\mathrm{T}$ cells were isolated from the spleen of WT and Tipe2-deficient mice using MagCellect Mouse Naive CD4 + T Cell Isolation Kit (R\&D Systems, Minneapolis, MN, USA). The purity of CD4 + T cells is about $95 \%$. Cells were stimulated with plate-bound anti-CD3 $(1 \mu \mathrm{g} / \mathrm{ml})$ plus soluble antiCD28 $(1 \mu \mathrm{g} / \mathrm{ml})$ with or without NF- $\kappa$ B inhibitor Bay 11-7082. Cells were collected at various time points and either used for RNA extraction or apoptosis analysis. Bone marrow-derived macrophages were stimulated with $100 \mathrm{ng} / \mathrm{ml}$ LPS with or without NF- $\kappa$ B inhibitor Bay 11-7082. After $4 \mathrm{~h}$, cells were collected for RNA extraction or protein preparation.

Preparation of cell extract and immunoblotting. The nuclear and cytoplasmic extracts from bone marrow-derived macrophages were prepared, as per the manufacturer's instruction (Active Motif, Carlsbad, CA, USA). Samples were loaded to $12 \%$ SDS-PAGE gels and subjected to electrophoresis. Proteins were transferred to nitrocellulose membranes and subsequently probed using antibody for Tipe2, $\beta$-actin (Sigma-Aldrich, St. Louis, MO, USA) or histone (Cell Signaling Technology, Danvers, MA, USA). a

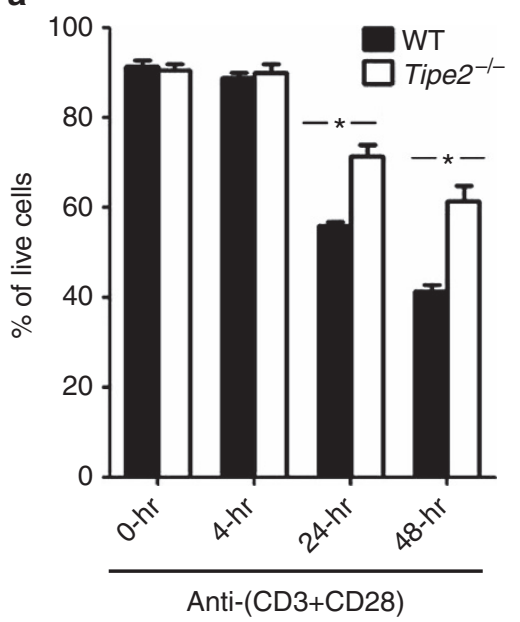

b

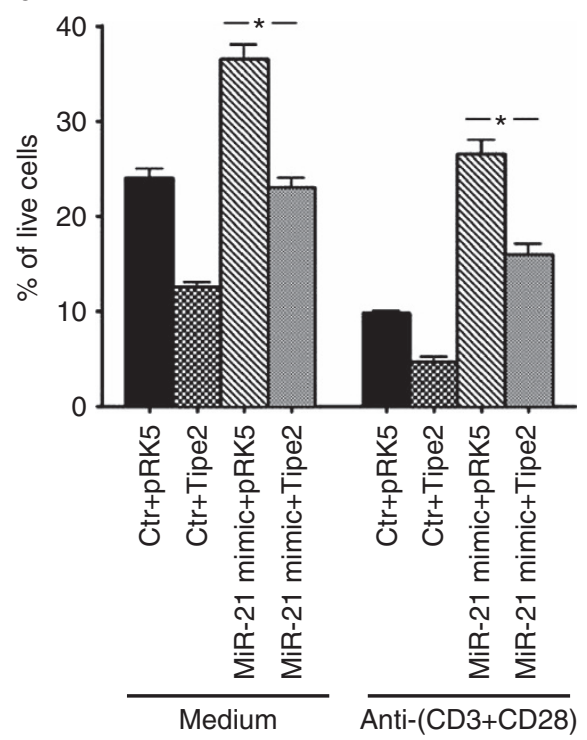

Figure 6 Tipe2 deficiency in T cells renders them resistant to death and miR-21 regulates T-cell apoptosis through Tipe2. (a) Splenic naive CD4 + T cells were isolated from WT and Tipe2 ${ }^{-1-}$ mice $(n=3)$ and either untreated or treated with plate-bound anti-CD3 $(1 \mu \mathrm{g} / \mathrm{ml})$ and soluble anti-CD28 $(1 \mu \mathrm{g} / \mathrm{ml})$ for the indicated times. Cells were then stained with annexin $V$ and $7 A A D$, and the degree of apoptosis was analyzed by flow cytometry. (b) EL4 cells were transfected with miR-21 mimic or negative control together with Tipe2-overexpressing construct or an empty vector. After $24 \mathrm{~h}$, cells were either untreated or treated with plate-bound anti-CD3 $(1 \mu \mathrm{g} / \mathrm{ml})$ and anti-CD28 (1 $\mu \mathrm{g} / \mathrm{ml})$. After $48 \mathrm{~h}, \mathrm{cells}$ were stained with annexin $V$ and $7 A A D$, and the degree of apoptosis was analyzed by flow cytometry. ${ }^{*} P<0.01$. Data are representative of three independent experiments 


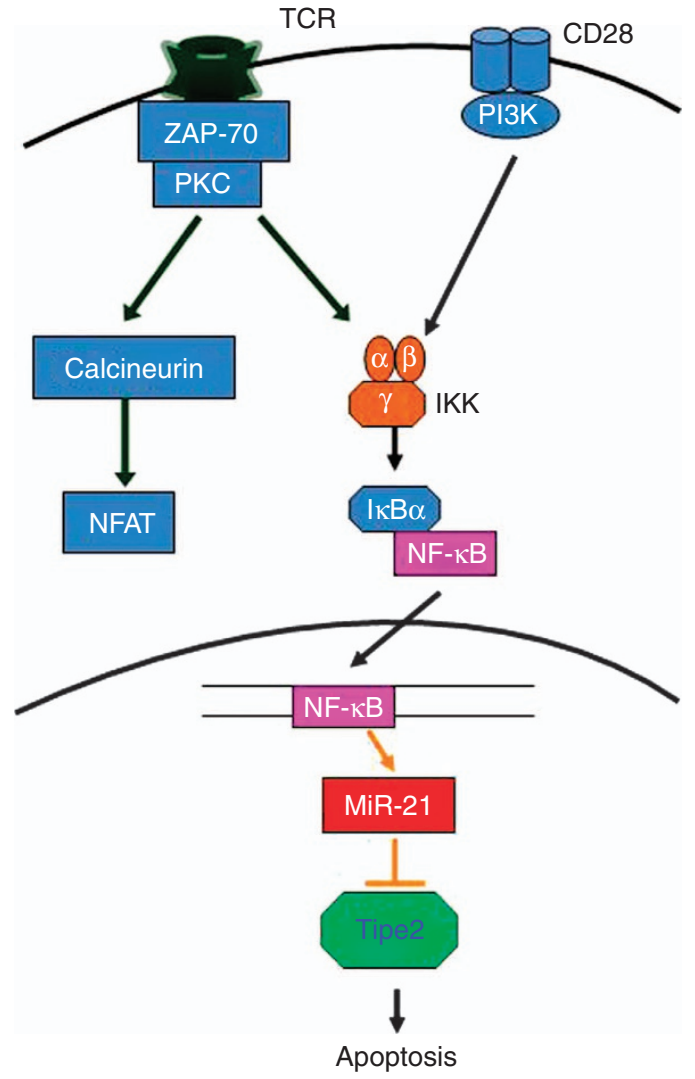

Figure $7 \quad \mathrm{NF}-\kappa \mathrm{B}$ inhibits activation-induced T-cell apoptosis through the miR21-Tipe2 axis. TCR and anti-CD28 stimulation activate NF-KB through IKK (by degrading the inhibitor protein $\mathrm{I}_{\kappa} \mathrm{B}$ ). After activation, NF- $\kappa \mathrm{B}$ translocates into the nucleus and turns on its target genes, including miR-21. MiR-21 in turn degrades Tipe2 and inhibits activation-induced T-cell apoptosis

ChIP assay. ChIP was performed using the ChIP assay kit, as per the manufacturer's instructions (Millipore, Billerica, MA, USA). In brief, cells were fixed with $1 \%$ formaldehyde at room temperature for $10 \mathrm{~min}$ and lysed in lysis buffer. DNA was then fragmented by sonication. After preclearance for $1 \mathrm{~h}$ at $4{ }^{\circ} \mathrm{C}$ with salmon sperm DNA-saturated protein A-agarose, chromatin solutions were immunoprecipitated overnight at $4^{\circ} \mathrm{C}$ using $1 \mu \mathrm{g}$ of rabbit antibodies to $\mathrm{p} 65$, RNA Polymerase II (Santa Cruz Biotechnology Inc., Santa Cruz, CA, USA), or control rabbit lgG. Input and immunoprecipitated chromatins were incubated for $4 \mathrm{~h}$ at $65^{\circ} \mathrm{C}$ to reverse crosslinks. After proteinase $\mathrm{K}$ digestion, DNA was extracted with phenol/chloroform and precipitated with ethanol. ChIP DNA was then analyzed by PCR with the following primer set: miR-21-P-F, $5^{\prime}$-GACACAAGCA TAAGTCATTTC-3'; miR-21-P-R, 5'-GCTGAGACTGCACACTGCTG-3'.

Nucleotide pull-down assay. Bone marrow-derived macrophages were stimulated with $100 \mathrm{ng} / \mathrm{ml}$ LPS for $4 \mathrm{~h}$. The cells were resuspended in lysis buffer (20 mM HEPES, $420 \mathrm{mM} \mathrm{NaCl}, 1.5 \mathrm{mM} \mathrm{MgCl}, 0.2 \mathrm{mM}$ EDTA, $1 \mathrm{mM}$ DTT and $0.1 \%$ Nonidet P-40) with protease inhibitors, and incubated on ice for $15 \mathrm{~min}$. Insoluble materials were removed by centrifugation. Hundred micrograms of lysate protein was diluted with dilution buffer (which is the same as the aforementioned lysis buffer, but without $\mathrm{NaCl}$ ) and incubated with $10 \mu \mathrm{g}$ of poly(deoxyinosinicdeoxycytidylic acid) (Roche, Indianapolis, IN, USA) and $50 \mu$ l of streptavidinagarose beads (Sigma-Aldrich) carrying biotinylated oligonucleotides (as described at the end of this section) for $3 \mathrm{~h}$ at $4{ }^{\circ} \mathrm{C}$. The beads were washed two times with dilution buffer, resuspended in $50 \mu \mathrm{l} 2 \times$ SDS sample loading buffer (Bio-Rad Laboratories, Hercules, CA, USA), and heated to $95^{\circ} \mathrm{C}$ for $10 \mathrm{~min}$. The eluants were resolved by SDS-PAGE. P65 was detected by immunoblotting with specific antibodies against p65 (Santa Cruz Biotechnology Inc.). The oligonucleotides containing either the WT or mutated NF- $\kappa \mathrm{B}$ binding sites (underlined sequences) used in this study are as follows: miR-21-NF- $\kappa$ B no. 1, $5^{\prime}$-GTGATAAATGTGGGACT TCTCAGAAGTCAT-3'; miR-21-NF- $\kappa$ B no. 1 mutant, 5'-GTGATAAATGTATAACTT
CTCAGAAGTCAT-3'; miR-21-NF- $\kappa$ B no. 2, 5'-AGGATGACGCAGGGGTTGTCCTA ATAAGGAC-3'; miR-21-NF- $\kappa$ B no. 2 mutant, $5^{\prime}$-AGGATGACGCAATAATTGTCCTA ATAAGGAC-3'

Luciferase assay. The fragments from miR-21 promoter containing either the WT or mutated NF- $\kappa$ B binding sites were cloned into the pGL3-basic vector (Promega). RAW264.7 cells were transiently transfected with the constructs mentioned above using Lipofectamine LTX transfection reagent (Life Technologies). After $24 \mathrm{~h}$, cells were treated with or without $100 \mathrm{ng} / \mathrm{ml}$ LPS for $6 \mathrm{~h}$, and the luciferase activities of total cell lysates were measured using the Dual-luciferase reporter assay system (Promega). To determine that Tipe2 is a target of miRNAs, a 500 bp fragment $(-400$ to +100$)$ from Tipe2 promoter was cloned into pGL3-basic vector. Then, a 475 bp fragment from Tipe2 $3^{\prime}$-UTR $(+648$ to +1122$)$ or serial deleted fragments from Tipe2 coding region $(+307$ to +644 ) were cloned into the $B g l l$ and $B a m H 1$ site downstream of the firefly luciferase gene but upstream of the polyA signal. EL4 cells were transiently transfected with the constructs mentioned above using Lipofectamine LTX transfection reagent (Life Technologies). After $24 \mathrm{~h}$, cells were treated with PMA and ionomycin for $4 \mathrm{~h}$, and the luciferase activities of total cell lysates were measured as mentioned above. Co-transfection of the Renilla luciferase expression vector pRL-TK (Promega) was used as an internal control for all reporter experiments. Site-directed mutagenesis of miR-21 binding site was performed using the QuikChange kit (Agilent Technologies, Inc., Santa Clara, CA, USA) according to the manufacturer's instructions. DNA sequencing was used to confirm the mutated nucleotides.

Statistical analysis. The significance of the differences in gene expression, luciferase activity, and rate of apoptosis was determined by Student's unpaired t-test.

\section{Conflict of Interest}

The authors declare no conflict of interest.

Acknowledgements. We thank Yael Gus for reagents and valuable discussions, and Jennifer DeVirgiliis for technical support. This study was supported by the National Institutes of Health, USA (AI-077533) and Kongque antibody drug program grant, Shenzhen, China.

\section{Authors contribution}

QR and YHC designed research; QR, PW, TW, MW, TF, SW, DJ and JQ performed research; XW, HS and WS contributed reagents/analytic tools; and QR and YHC analyzed data and wrote the paper. All authors approved the final version of the manuscript.

1. Bernstein E, Kim SY, Carmell MA, Murchison EP, Alcorn H, Li MZ et al. Dicer is essential for mouse development. Nat Genet 2003; 35: 215-217.

2. Calin GA, Croce CM. MicroRNA signatures in human cancers. Nat Rev Cancer 2006; 6 : 857-866.

3. He L, Hannon GJ. MicroRNAs: small RNAs with a big role in gene regulation. Nat Rev Genet 2004; 5: 522-531.

4. Muljo SA, Ansel KM, Kanellopoulou C, Livingston DM, Rao A, Rajewsky K. Aberrant T cell differentiation in the absence of Dicer. J Exp Med 2005; 202: 261-269.

5. Sonkoly E, Stahle M, Pivarcsi A. MicroRNAs and immunity: novel players in the regulation of normal immune function and inflammation. Semin Cancer Biol 2008; 18: 131-140.

6. Xiao C, Rajewsky K. MicroRNA control in the immune system: basic principles. Cell 2009; 136: 26-36.

7. Schotte D, Pieters R, Den Boer ML. MicroRNAs in acute leukemia: from biological players to clinical contributors. Leukemia 2012; 26: 1-12.

8. Bartel DP. MicroRNAs: target recognition and regulatory functions. Cell 2009; 136: 215-233.

9. Nelson P, Kiriakidou M, Sharma A, Maniataki E, Mourelatos Z. The microRNA world: small is mighty. Trends Biochem Sci 2003; 28: 534-540.

10. Belair C, Darfeuille F, Staedel C. Helicobacter pylori and gastric cancer: possible role of microRNAs in this intimate relationship. Clin Microbiol Infect 2009; 15: 806-812.

11. Cho WC. OncomiRs: the discovery and progress of microRNAs in cancers. Mol Cancer 2007; 6: 60 .

12. Gramantieri L, Fornari F, Callegari E, Sabbioni S, Lanza G, Croce CM et al. MicroRNA involvement in hepatocellular carcinoma. J Cell Mol Med 2008; 12: 2189-2204. 
13. Selcuklu SD, Donoghue MT, Spillane C. miR-21 as a key regulator of oncogenic processes. Biochem Soc Trans 2009; 37: 918-925.

14. Wang Y, Lee CG. MicroRNA and cancer-focus on apoptosis. J Cell Mol Med 2009; 13: 12-23.

15. Chan JA, Krichevsky AM, Kosik KS. MicroRNA-21 is an antiapoptotic factor in human glioblastoma cells. Cancer Res 2005; 65: 6029-6033.

16. Frezzetti D, De Menna M, Zoppoli P, Guerra C, Ferraro A, Bello AM et al. Upregulation of miR-21 by Ras in vivo and its role in tumor growth. Oncogene 2011; 30: 275-286.

17. Hatley ME, Patrick DM, Garcia MR, Richardson JA, Bassel-Duby R, van Rooij E et al. Modulation of K-Ras-dependent lung tumorigenesis by MicroRNA-21. Cancer Cell 2010; 18: 282-293.

18. Krichevsky AM, Gabriely G. miR-21: a small multi-faceted RNA. J Cell Mol Med 2009; 13: 39-53.

19. Morrisey EE. The magic and mystery of miR-21. J Clin Invest 2010; 120: 3817-3819.

20. Si ML, Zhu S, Wu H, Lu Z, Wu F, Mo YY. miR-21-mediated tumor growth. Oncogene 2007; 26: 2799-2803.

21. Bostjancic E, Glavac D. Importance of microRNAs in skin morphogenesis and diseases. Acta Dermatovenerol Alp Panonica Adriat 2008; 17: 95-102.

22. Wu F, Zikusoka M, Trindade A, Dassopoulos T, Harris ML, Bayless TM et al. MicroRNAs are differentially expressed in ulcerative colitis and alter expression of macrophage inflammatory peptide-2 alpha. Gastroenterology 2008; 135: 1624-1635.

23. Ma X, Kumar M, Choudhury SN, Becker Buscaglia LE, Barker JR, Kanakamedala K et al. Loss of the miR-21 allele elevates the expression of its target genes and reduces tumorigenesis. Proc Natl Acad Sci USA 2011; 108: 10144-10149.

24. Zhou X, Ren Y, Moore L, Mei M, You Y, Xu P et al. Downregulation of miR-21 inhibits EGFR pathway and suppresses the growth of human glioblastoma cells independent of PTEN status. Lab Invest 2010; 90: 144-155.

25. Lu TX, Hartner J, Lim EJ, Fabry V, Mingler MK, Cole ET et al. MicroRNA-21 limits in vivo immune response-mediated activation of the IL-12/IFN-gamma pathway, Th1 polarization, and the severity of delayed-type hypersensitivity. J Immunol 2011; 187: 3362-3373.

26. Meisgen F, Xu N, Wei T, Janson PC, Obad S, Broom $O$ et al. MiR-21 is up-regulated in psoriasis and suppresses T cell apoptosis. Exp Dermatol 2012; 21: 312-314.

27. Vicinus B, Rubie C, Faust SK, Frick VO, Ghadjar $\mathrm{P}$, Wagner M et al. miR-21 functionally interacts with the 3'UTR of chemokine CCL20 and down-regulates CCL20 expression in miR-21 transfected colorectal cancer cells. Cancer Lett 2012; 316: 105-112.

28. van der Fits L, van Kester MS, Qin Y, Out-Luiting JJ, Smit F, Zoutman WH et al. MicroRNA21 expression in CD4 + T cells is regulated by STAT3 and is pathologically involved in Sezary syndrome. J Invest Dermatol 2011; 131: 762-768.

29. Holtzman MJ, Green JM, Jayaraman S, Arch RH. Regulation of T cell apoptosis. Apoptosis 2000; 5: 459-471.

30. Lenardo M, Chan KM, Hornung F, McFarland H, Siegel R, Wang $\mathrm{J}$ et al. Mature T lymphocyte apoptosis-immune regulation in a dynamic and unpredictable antigenic environment. Annu Rev Immunol 1999; 17: 221-253.

31. Schütze S, Potthoff K, Machleidt T, Berkovic D, Wiegmann K, Krönke M. TNF activates NFkappa B by phosphatidylcholine-specific phospholipase C-induced "acidic" sphingomyelin breakdown. Cell 1992; 71: 765-776.

32. Barkett M, Gilmore TD. Control of apoptosis by Rel/NF-kappaB transcription factors. Oncogene 1999; 18: 6910-6924.

33. Zheng Y, Vig M, Lyons J, Van Parijs L, Beg AA. Combined deficiency of p50 and cRel in $\mathrm{CD} 4+\mathrm{T}$ cells reveals an essential requirement for nuclear factor kappaB in regulating mature T cell survival and in vivo function. J Exp Med 2003; 197: 861-874.

34. Zhang G, Hao C, Lou Y, Xi W, Wang X, Wang Y et al. Tissue-specific expression of TIPE2 provides insights into its function. Mol Immunol 2010; 47: 2435-2442.

35. Zhang $L$, Shi $Y$, Wang $Y$, Zhu F, Wang $Q$, Ma $C$ et al. The unique expression profile of human TIPE2 suggests new functions beyond its role in immune regulation. Mol Immunol 2011; 48: 1209-1215.

36. Li D, Song L, Fan Y, Li X, Li Y, Chen J et al. Down-regulation of TIPE2 mRNA expression in peripheral blood mononuclear cells from patients with systemic lupus erythematosus. Clin Immunol 2009; 133: 422-427.

37. Sun H, Gong S, Carmody RJ, Hilliard A, Li L, Sun J et al. TIPE2, a negative regulator of innate and adaptive immunity that maintains immune homeostasis. Cell 2008; 133 : 415-426.

38. Gus-Brautbar $Y$, Johnson D, Zhang L, Sun H, Wang $P$, Zhang $S$ et al. The antiinflammatory TIPE2 is an inhibitor of the oncogenic Ras. Mol Cell 2012; 45: 610-618.
39. Niu J, Shi Y, Tan G, Yang CH, Fan M, Pfeffer LM et al. DNA damage induces NF-kappaBdependent microRNA-21 up-regulation and promotes breast cancer cell invasion. $J$ Biol Chem 2012; 287: 21783-21795.

40. Ribas J, Lupold SE. The transcriptional regulation of miR-21, its multiple transcripts, and their implication in prostate cancer. Cell Cycle 2010; 9: 923-929.

41. Shin VY, Jin $\mathrm{H}, \mathrm{Ng}$ EK, Cheng AS, Chong WW, Wong CY et al. NF-kappaB targets miR-16 and miR-21 in gastric cancer: involvement of prostaglandin $E$ receptors. Carcinogenesis 2011; 32: 240-245.

42. Fujita S, Ito T, Mizutani T, Minoguchi S, Yamamichi N, Sakurai K et al. miR-21 Gene expression triggered by AP-1 is sustained through a double-negative feedback mechanism. J Mol Biol 2008; 378: 492-504.

43. Iliopoulos D, Jaeger SA, Hirsch HA, Bulyk ML, Struhl K. STAT3 activation of miR-21 and miR-181b-1 via PTEN and CYLD are part of the epigenetic switch linking inflammation to cancer. Mol Cell 2010; 39: 493-506.

44. Misawa A, Katayama R, Koike S, Tomida A, Watanabe T, Fujita N. AP-1-Dependent miR21 expression contributes to chemoresistance in cancer stem cell-like SP cells. Oncol Res 2010; 19: 23-33.

45. Rozovski U, Calin GA, Setoyama T, D'Abundo L, Harris DM, Li P et al. Signal transducer and activator of transcription (STAT)-3 regulates microRNA gene expression in chronic lymphocytic leukemia cells. Mol Cancer 2013; 12: 50.

46. Darido C, Georgy SR, Wilanowski T, Dworkin S, Auden A, Zhao Q et al. Targeting of the tumor suppressor GRHL3 by a miR-21-dependent proto-oncogenic network results in PTEN loss and tumorigenesis. Cancer Cell 2011; 20: 635-648.

47. Frankel LB, Christoffersen NR, Jacobsen A, Lindow M, Krogh A, Lund AH. Programmed cell death 4 (PDCD4) is an important functional target of the microRNA miR-21 in breast cancer cells. J Biol Chem 2008; 283: 1026-1033.

48. Frey MR, Carraro G, Batra RK, Polk DB, Warburton D. Sprouty keeps bowel kinases regular in colon cancer, while miR-21 targets Sprouty. Cancer Biol Ther 2011; 11: 122-124

49. Kwak HJ, Kim YJ, Chun KR, Woo YM, Park SJ, Jeong JA et al. Downregulation of Spry2 by miR-21 triggers malignancy in human gliomas. Oncogene 2011; 30: 2433-2442.

50. Liu M, Wu H, Liu T, Li Y, Wang F, Wan H et al. Regulation of the cell cycle gene, BTG2, by miR-21 in human laryngeal carcinoma. Cell Res 2009; 19: 828-837.

51. Qin W, Zhao B, Shi Y, Yao C, Jin L, Jin Y. BMPRIl is a direct target of miR-21. Acta Biochim Biophys Sin (Shanghai) 2009; 41: 618-623.

52. Zheng J, Xue H, Wang $T$, Jiang $Y$, Liu B, Li J et al. miR-21 downregulates the tumor suppressor P12 CDK2AP1 and stimulates cell proliferation and invasion. J Cell Biochem 2011; 112: 872-880.

53. Liu C, Li B, Cheng Y, Lin J, Hao J, Zhang S et al. MiR-21 plays an important role in radiation induced carcinogenesis in BALB/c mice by directly targeting the tumor suppressor gene Big-h3. Int J Biol Sci 2011; 7: 347-363.

54. Liu M, Tang Q, Qiu M, Lang N, Li M, Zheng Y et al. miR-21 targets the tumor suppressor $\mathrm{RhoB}$ and regulates proliferation, invasion and apoptosis in colorectal cancer cells. FEBS Lett 2011; 585: 2998-3005.

55. Kida K, Nakajima M, Mohri T, Oda Y, Takagi S, Fukami T et al. PPARalpha is regulated by miR-21 and miR-27b in human liver. Pharm Res 2011; 28: 2467-2476.

56. Forman JJ, Coller HA. The code within the code: microRNAs target coding regions. Cell Cycle 2010; 9: 1533-1541.

57. Huang S, Wu S, Ding J, Lin J, Wei L, Gu J et al. MicroRNA-181a modulates gene expression of zinc finger family members by directly targeting their coding regions. Nucleic Acids Res 2010; 38: 7211-7218.

58. Hu H, Li Y, Gu J, Zhu X, Dong D, Yao J et al. Antisense oligonucleotide against miR-21 inhibits migration and induces apoptosis in leukemic K562 cells. Leuk Lymphoma 2010; 51 $694-701$.

59. Li Y, Zhu X, Gu J, Dong D, Yao J, Lin C et al. Anti-miR-21 oligonucleotide sensitizes leukemic K562 cells to arsenic trioxide by inducing apoptosis. Cancer Sci 2010; 101: 948-954.

(c) (1) $(9)$ Cell Death and Disease is an open-access journal (c) licensed under a Creative Commons Attribution-NonCommercialNoDerivs 3.0 Unported License. To view a copy of this license, visit http://creativecommons.org/licenses/by-nc-nd/3.0/ 